\title{
Elinor ACCAMPO, Blessed Motherhood. Bitter Fruit. Nelly Roussel and the Politics of Female Pain in Third Republic France, Baltimore, Johns Hopkins University Press, 2006, 312 pages.
}

\section{Rebecca Rogers}

\section{OpenEdition}

\section{Journals}

Édition électronique

URL : https://journals.openedition.org/clio/6993

DOI : $10.4000 /$ clio.6993

ISSN : 1777-5299

Éditeur

Belin

\section{Édition imprimée}

Date de publication : 1 novembre 2007

Pagination : 232-264

ISBN : 978-2-85816-940-5

ISSN : 1252-7017

\section{Référence électronique}

Rebecca Rogers, «Elinor ACCAMPO, Blessed Motherhood. Bitter Fruit. Nelly Roussel and the Politics of Female Pain in Third Republic France, Baltimore, Johns Hopkins University Press, 2006, 312 pages. », Clio. Femmes, Genre, Histoire [En ligne], 26 | 2007, mis en ligne le 14 avril 2008, consulté le 24 avril 2022. URL : http://journals.openedition.org/clio/6993 ; DOl : https://doi.org/10.4000/clio.6993

Ce document a été généré automatiquement le 24 avril 2022

Tous droits réservés 


\title{
Elinor ACCAMPO, Blessed Motherhood. Bitter Fruit. Nelly Roussel and the Politics of Female Pain in Third Republic France, Baltimore, Johns Hopkins University Press, 2006, 312 pages.
}

\author{
Rebecca Rogers
}

1 L'écriture de biographies est de nouveau à la mode, notamment dans l'histoire des femmes et du genre qui se publie outre-Manche et outre-Atlantique. Dans le sillage de ce que Jo Burr Margadant a nommé "The New Biography " ${ }^{1}$, Elinor Accampo s'est lancée dans l'entreprise biographique en choisissant la figure de Nelly Roussel (1878-1922), militante féministe, libre-penseuse, pacifiste et néo-malthusienne. En analysant aussi bien sa doctrine que les réactions qu'elle a suscitées, l'historienne cherche à comprendre «le système du genre en France et son rapport avec la culture politique ». Chemin faisant, elle nous livre un portrait passionnant d'une femme aux facettes multiples qui méritait bien une biographie comme celles déjà publiées de Hubertine Auclert, Madeleine Pelletier et Clémence Royer.

2 Structuré de manière classique, le livre suit l'existence de Nelly Roussel de sa naissance dans une famille bourgeoise de la droite bien-pensante à sa mort après la guerre, au terme d'une décennie de souffrances. Comme Nelly Roussel a consciemment voulu fabriquer une image d'elle-même tout au long de sa courte vie, elle a préservé ses lettres, ses agendas, ses conférences et les écrits de journalistes la concernant, livrant à l'œil du biographe une importante collection de textes et d'images portant aussi bien sur sa vie privée que publique. Le lecteur la suit dans ses velléités d'actrice en tant que jeune fille, puis comme fiancée, épouse, mère et femme moderne. Sa conférence «L'éternelle sacrifiée», prononcée 64 fois entre 1905 et 1908, sert de fil rouge à la 
biographie, puisque E. Accampo insiste beaucoup sur le rôle de la douleur dans son identité. Oratrice talentueuse, elle utilise l'idée de la femme sacrifiée pour exprimer sa protestation contre le lot des femmes, condamnées par leur sexe à subir la douleur qui vient par la maternité, la maladie et la guerre.

E. Accampo mêle habilement les aspects privés et publics de son personnage, montrant en particulier l'importance du soutien de son mari, le sculpteur, libre-penseur et francmaçon Henri Godet. Il l'aidera à mener une vie publique - en gardant les enfants, en fabriquant des affiches, en la conseillant sur le sujet de ses conférences en fonction du lieu -, mais il exercera aussi son influence sur l'évolution de l'image publique qu'elle projette. En effet, Nelly Roussel est surtout connue pour ses positions néomalthusiennes, qui sont difficiles à faire admettre dans la culture nationaliste de l'avant-guerre, surtout dans le contexte démographique français. Proclamer le droit des femmes à contrôler leur propre corps et à faire ainsi le choix de la maternité n'était pas un message facile à faire passer et c'est Godet qui l'encouragera à incorporer dans ses conférences une image plus maternelle à laquelle plus de femmes pourraient adhérer. Cette stratégie a du succès auprès des publics libres-penseurs, instituteurs et ouvriers auxquels elle s'adresse, comme l'analyse des lettres qui lui sont adressées l'atteste. La cartographie de ses conférences est une confirmation impressionnante de la vie publique de cette femme pour qui le voyage et le contact avec un public donnent sens à ses engagements et à sa vie. Elle sillonne les routes de France prêchant le refus du sacrifice et le refus de la douleur comme condition inéluctable pour les femmes. De manière fort précoce, elle plaide pour la reconnaissance du travail maternel, en disant que les mères sont les moins bien payées de tous les ouvriers.

L'un des tours de force de cette biographie est de révéler la facette privée de Nelly Roussel. Malade d'une tuberculose mal diagnostiquée, elle souffre à partir de 1908 de troubles digestifs et de dépression qui entraînent de longs moments d'inaction et des séjours au vert. Ses médecins la traitent comme une neurasthénique, l'obligeant au repos et aux séjours en famille, source de souffrance supplémentaire pour cette femme dont le rapport avec la maternité n'est pas simple. Ses lettres décrivent son fils comme son "terrible tourmenteur" et elle s'épanouit peu dans les joies de la domesticité familiale, domesticité souvent difficile à cause de problèmes financiers, d'absence de gardes d'enfants et de la vie rapprochée avec la famille étendue. Cette femme qui passera sa vie à appeler à la maternité choisie semble avoir vécu sa propre maternité avec beaucoup de contradictions.

Malgré son succès d'oratrice, son combat aura peu d'impact sur la politique française, d'autant plus que les années 1920 sont marquées par le retour de l'éternel féminin avec la loi de juillet 1920 qui interdit la vente des moyens contraceptifs et la propagande en leur faveur. La biographe conclut ainsi à la trop grande modernité du message de Roussel qui ne sera finalement repris qu'avec le mouvement féministe des années 1960 et 1970. La plongée proposée dans la complexité de cette vie de femme illustre la richesse d'une approche biographique qui établit ainsi les liens entre les combats féministes, leur vécu corporel et la culture politique de l'époque. Si nous avons parfois du mal à imaginer nos "grandes dames " souffrantes et malades, l'historienne nous rappelle à quel point cette souffrance faisait partie du lot commun des femmes et de leurs familles, et que donner corps à cette dimension de l'histoire mérite notre attention. 


\section{NOTES}

1.J.B. Margadant (ed.) The New Biography. Performing Femininity in NineteenthCentury France, Berkeley, University of California Press, 2000. 